\section{ORIGIIAT COMOUTICATIOHS.}

\section{NOTES ON CHRONIC HEART-DISEASE.}

By ALEXANDER HARVEY, M.D.Edin., late Physician to the Aberdeen Royal Infirmary, and formerly Lecturer on the Practice of Medicine in the Unirersity and King's College of $\Delta$ berdeen.

Ir the following notes, an attempt is made to exhibit within as small a compass as possible, and in a form approaching the tabular, the leading facts connected with the pathology, diagnosis, and prognosis, of the more common organic affections of the heart. Imperfect as the notes are, the suthor is not without hope that they may be of service to some of his colleagues in the Association, who, though familiar with the subject of heart-disease, may not always be able at once or readily to call to mind such particulars respecting it as they must often have occasion for in the course of their practice, and which they may not always have time or opportunity to collect from larger treatises.

It may be added, that the notes were originally drawn up for the students attending the author's class, and delivered to them as a recapitulation of the facts just previously detailed at greater length in the lectures; and that the materials of them are chiefly taken from Dr. Watson's Lectures and Dr. Alison's Outlines of Pathology and Practice of Medicine, the works used in the clase as text-books.

\section{DISEASE OF VALVES AND ORIFICES.}

1. The valves and orifices of the left side of the heart are at least twenty times more liable to disease than the valves and orifices of the right side.

Disease of the semilunar pulmonary valves is so rare as to be matter of pathological interest merely. Disease of the tricuspid valves is more frequently, although still seldom, met with; and still seldomer without coexisting disease of either the aortic or mitral valves.

II. In early life and in women, the mitral valve and corresponding auriculo-ventricular orifice are oftenest diseased ; in advanced life and in men, the aortic. In many cases, at all ages and in both sexes, the two sets of valves and openings are simultaneously diseased.

III. The diseased states of the valves and orifices are mostly the result of (a) antecedent endocarditis of rheumatic origin, and consist of concretions forming on the valves; or (b) mere perversion of nutrition, independent of inflammation, and occurring in connexion with atheromatous and other kinds of deposit in the aorta and arteries generally.

IV. The effects of these changes on the functions of the valves and orifices are twofold:-

1. By contracting and narrowing the orifice, to impede or obstruct the passage of the blood (valvular obstruction, obstructive disease of valves).

2. By thickening, corrugating, and shortening the valres, to make the orifice more or less permanently patent, and allow regurgitation or reflux of blood (valvular insufficiency, valvular patency, regurgitant disease of valves).

7. Valvular obstruction and valvular insufficiency often exist separately, but are oftener coexistent in the same valve. Each of them may obtain in very different degrees, and the two may be very variously combined.

vi. In a very few cases, the cause of patency is preternatural widening of the orifice without disease, but with no adequate extension by growth, of the valves; and, in a few others, it is owing to disease with shortening of the chordm tendiner, the valves themselves being sound.

\section{DIBEASE OR WALLS AND CAVITIES (Hypertrophy and} Dilatation).

r. Hypertrophy and Dilatation may be either partial or general, oftenest partial. Dilatation, unaccompanied by ijpertrophy, is rare.
II. Hypertrophy and Dilatation are very generally w condary morbid states. They may bo produced by rariou causes:-

1. In a very few cases, by unknown causes, or causes unconnected with obvious change of structure elsewhere (primary).

2. By adhesion of the pericardium to the heart, consequent on plastic exudation from pericarditis.

3. By preternatural widening, with or without change of structure, of the ascending aorta.

4. By diseased states of the valves. This is the most common cause.

III. The rationale of their production may be thus stated:-

1. Disease of the valves, widening of the aorta, adhesion of the pericardium, create a demand for increased action of the heart; and this increased action, in a constitution otherwise healthy, leads to increased nutrition of the organ. The walls of the heart are thereby gradually increased in bulk and in contractile power (simple hypertrophy).

2. When, along with this increased action, there is (a) a full quantity of blood in the body, the cavities of the heart are gradually dilated at the same time that their walls are thickened (hypertrophy woith dilatation, eccentric hypertrophy). But (b) when the quantity of circulating blood is much diminished, the tonic contraction of the thickened fibres of the heart, which are no longer distended, leads to a diminution in the size of its cavities (concentric hypertrophy). This is rarely met with, except cither as a congenital affection, or, in connexion with the rigor mortis, as a temporary post mortem condition.

3. Dilatation without hypertrophy, consequent on obstructive disease of the valves, occurs chiefly $(a)$ in a weakly habit of body, when the excitement of the heart by the preternatural amount of its stimulus is feeble; but (b) it may be produced, in a habit otherwise healthy, by mere morbid debility of the muscular fibres of the heart, as after some cases of rheumatism affecting them.

Iv. In the great majority of cases, it is the left ventricle that is first and chiefly affected, and hypertrophy and dilatation combined (eccentric hypertrophy) that obtains, and in connexion with pre-existing mitral or aortic disease. With mitral disease, there is commonly rounding of the apex, and often simple hypertrophy merely; with aortic disease, there is elongation of the apex, and commonly eccentric hypertrophy.

Pure dilatation may affect either ventricle, oftenest perhaps the right, and that chiefly in females, and in such cases seems to occur in connexion rather with disease of lung (e.g., habitual asthma) than with diseased valres.

\section{DIAGNOSIS OF CHRONIC HEART-DISEASE.}

Diagnosis of Disease of Valves and Orifices. Practically, in at least nineteen out of twenty cases, the questions to be determined are, whether it be the mitral or the aortic valve that is diseased, or both; and whether the disease be of the nature of valvular obstruction, or of valvular insufficiency, or both. The diagnosis is mainly founded on these two things: first, a bruit or murmur heard, called, from its blowing character, bellows murmur, ‘r, from its seat being within the heart, endocardial murmur; and secondly, the state and character of the pulse at the wrist.

I. Bruit or murmur. Its import varies according (a) to the time when it is heard, (b) the place where it is best heard, and $(c)$ the direction in which it is conveyed furthest. The second and third may be taken together, and included under one head.

(a) The time when it is heard. This may be either with (or rather in place of) the first natural sound (systolic bruit); blood then passing from the left rentricle into either the aorta before, or the auricle behind: or with the second natural sound (diastolic bruit); blood then passing into the ventricle, from either the aorta before, or the auricle behind.

(b) The place and direction in which it is best heard and conveyed furthest. This may be either over the base of the 


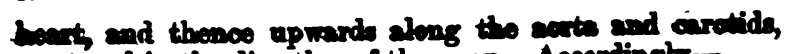
an and in the direction of the apex. Acecodingly-

1. Bruit, systolic and loudest at base, indicates obutaseo ire divense of the sortic valves or orifice.

\&. Bruit, astolic and loudest at apex, indicates sritral insufficiency (patency) with regurgitation.

2. Bruit, diastolic and loudest at base, indicates aartic insufficiency with regurgitation.

4. Bruit, diastolic and loudest at aper, indicates mitral obstruction. Rarely if ever heard.

* * Various combinations of these murmurs are semetimes heard, constituting double bruits. Their imaport is to be gathered from that of the single murmurs. Thus, e.g., there may be a systolic bruit, equally loud at the base and at the apex, indicating at once aortic obstruction and mitral insufficiency; or there may be a systolic and a diatolic bruit, both loudest at the base, and indicating aortic obstruction and aortic regurgitation.

II. The Pulse.

1. Pulse at wrist irregular, intermittent, unequal, and soft, small, or weak, indicates mitral disease, obstructive or regurgitant, particularly the latter, on which this condition of the pulse is specially dependent.

2. Putse regular, full, or hard, indicates aortic disease; if jerking and resilient, aortic insufficiency (with hypertrophy).

The foregoing ( $\mathrm{I}$ and $\mathrm{II}$ ) may be thus brieffy represented on a card carried in the pocket.*

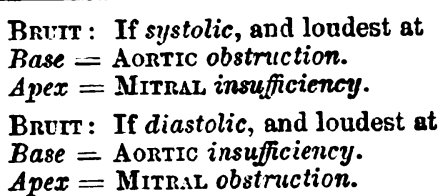

And on the reverse side of card :-

$$
\left.\begin{array}{l}
\text { Pulse: If rrgular, } \\
\text { Full, or strong, } \\
\text { Jerking, resilient. } \\
\text { Pulse: If irregular, } \\
\text { Intermittent, unequal, } \\
\text { Soft, small, weak. }
\end{array}\right\}=\text { Mirrsx disease. }
$$

Diagnosis of Disease of Walls and Cavities.

1. Of Hypertrophy.

1. The action of the heart preternaturally, sometimes excessively strong, with corresponding impulse felt on laying the hand or the ear over the præcordial region.

2. The sounds of the heart's action, and especially the first sound, less audible than natural,-abscured or muffled. II. Of Dilatation.

1. The action of the heart weak, somewhat undulatory, with indistinct impulse.

2. The sounds of the heart's action, and especially the first, preternaturally clear, short, or abrupt.

III. Of Hypertrophy and Dilatation.

With various modifications, as the one or the other condition predominates, of the abnormal impulse, and the abnormal sounds of the heart's action-

1. The area of the natural dulness on percussion increased, often with squareness of outline of this area.

2. The apex of the heart seen and felt to beat lower down than natural, often as low at the seventh or eighth ribs.

3. The præcordial region in some cases obviously bulging and prominent.

\section{PROGRESS AND RESULTS OF CHBONIC HEART DISEABE.} PBOGNOSI8.

I. It is important to discriminate between (a) the affec-

- See "Diagram of Morbid Sounds of the Heart", of whieh that in the taxt is only a mudification, nomtained in an excellent paper by my friend Dr. Mgour, of Aberdeen, "On Disense of the Heart, and the Dropsy following

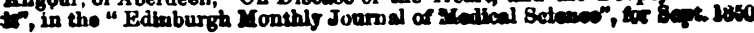

tion of the heart itself, and (B) the cecondary arections,

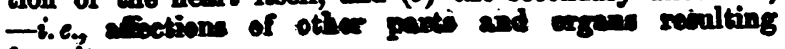
from it.

(a.) As time adrances, there occurs a gradual aggraration of the beart affection; an inerease of the Finviar obstruction or of the valvular insufficiency, or of both; and likewise an increase of the hypertrophy or of the dilatition, or of both.

(b.) Sooner or later secondary affections, of various kinds, extrinsic to the heart, supervene, e.g.,

1. Dyspneas; bronchitis; pneumonia; pulmonary hoo morrhage, with or without pulmonary apoplexy.

2. Enlargement of the liver, or of the liver and spleen; hoomatemesis.

3. Cephalalgis ; tinnitus ; rertigo ; syncope; epilepey ; epistaxis; cerebral hremorrhage; apoplexy; palsy.

4. Dropsical effusion; codema of face, or of face and hands, - of lungs; hydrothorax ; ascites ; ansearca of goneral dropsy.

5. Various combinations and successions of the foregoing.

II. Both the aggraration of the heart disease and the supervention of some secondary affection take place maxe surely and more quickly, in young and full-blooded individuals, than in those alreaily ald, or thin or emaciated.

III. As to the relation that obtains between the secondary affections and the diseased heart-

1. The connocting link betwoen them is the altered (abnormal) condition of the general circulation produced by the state of the heart. This condition may be one or other, or a combination of three kinds $(a)$, impeded renous current behind (pulmonic and systemic), as in mitral disease, whether obstructive or regurgitant; or (b) undue impulsion of the arterial current in advance, as in hypertrophy; or $(c)$ too feeble impulsion, as in purely passive dilatation of the ventricle.

2. Nevertheless, the diseased state of the heart and these effects of it on the general circulation are commonly only permanent predisposing couses, not the direct or exciting causes, of those secondary affections, - the immodiate causes of them (often in a great measure avoidable) being intemperance, over exertion and fatigue, mental emotion, and especially exposure to cold or cold and wet.

3. Some of the secondary affections are themselves the occasion, or concurrent and cooperating causes, of certain other secondary affections, e.g., bronchitis of cedema of the lungs, or of general dropoy ; enlargement of the liver, or of the liver and spleen - of ascites, hæmatomesis, epistaxis, apoplexy; or consolidation of lung and enlargement of the liver combined, with bronchitis- of general dropsy.

IV. The worst kind of heart affection is that in whioh there is at once obstructive and regurgitant disease of the mitral valve, because the most effectual in deranging the general circulation, and the moat fruitful therefore of secondary affections. The least unfavourable is a diseased state of the aortic valve only, with moderate hypertrophy of the left ventricle; the hypertrophy, though reckaned : diseased state being, in fact, a provision of nature for overcoming the resistance offered to the exit of the blood.

Insufficiency of the mitral valve, however, with much hypertrophy of the left ventricle, is very hazardous; the hypertrophy in this case enhancing the evil naturally attendant on the patency of the valve.

v. When death ensues, the fatal event may take place suddenly, in the way of syncope, and be directly referrible to the diseased state of the heart; or it may take place more gradually through the medium of some secondary affection, and in very various modes, -in the way of asthenia, or in the way of coma, or in the way of asphyxia, -according to circumstances.

vi. The prognosis in any case must mainly be based upon, and may in general readily be determined from,-

1. The kind and extent of heart affection.

2. The tendency that many appear towards socondary afection; and the kind and extent of this.

3. The age and bodily habit of the patient. 
1. We degnes to which the habits and circumotances of a pritint $\operatorname{con}$ be controlled and regulated, and the proWib refency of the remedies applied, with the view in ropect of them all $(a)$ of returding the progress of the wint affection, - (b) of warding off secondary affections, and $(c)$ of remoring these when they supervene: these creral objects furmishing at the same time the main indiculions of TBEATXEST.

Southampton, July 28,1854

\section{CLINICAL REMARKS ON CYSTIC SARCOMA AND CANCER OF THE FEMALE BREAST.}

\section{By JOSEPH SAMPSON GAMGEE.}

Swow as must always be the march of knowledge, it is somewhat depressing to reflect that in the science of medicine, which more closely than any other affects the welfare of men, there are special reasons which obstruct progress in addition to those operating in other departments of knowledge. Such is the complexity of the animal organisation, so numerous and difficult are the laws which govern it in health and in disease, that even when to its study can be brought the aid of physical instruments, the task is one of uncommon labour, beset with extraordinary fallacies, as even the most sceptic may satisfy himself, who reflects upon the history of the innovation and introduction into practice of the stethoscope and microscope. The former has achieved its victories, the battle of the latter is being fought. Though there is ample proof that but for the microscope a large number of pathological facts of clinical value, now known, would never have been discovered; though there is good reason to hope that we have barely tasted its fruits; many surgeons in high stations treat it lightly, while others openly deny its practical ntility. Cancer is the field on which its value to surgeons will in great measure have to be decided; and this will be immense, if, after ascertaining by microscopic investigation the anatomical characters of morbid grow ths and classifying these accordingly, it can be determined that the anatomical characters of cancer are as peculiar as their clinical history ; that a tumour not presenting the anatomical character of cancer does not entail upon its possessor any of the evils of this disease; and consequently that in prognoais, at least, immense aid will be afforded by the results of microscopic observation.

It seemed as if this great boon had resulted from the application of the microscope; but there are facts on record in the writings of Mr. Erichsen, Mr. Birkett, and Mr. Paget, which throw a great doubt upon the reality of the discovery, if they do not altogether prove that a benignant tumour, though completely removed by the knife, may be succeeded by an affection in anatomical characters and effects inseparable from secondary cancer. I do not assent to the validity of the proof, because impressed with the belief, that not only has not sufficient care been taken for excluding fallacy from the observation of the facts upon which it is founded, but that their impartial and rigorous study leads to conclusions opposed to those which the above named distinguished authorities have inferred from them.

I shall first relate the case which has given rise to the discussion.

Case. Catherine Edwardes, * aged 42, was admitted into University College Hospital, 9th June, 1851. She was married, and the mother of two children. She had always enjoyed good health and regular catamenia.

Bistory of the present Affection. Three years ago, she felt a small lump about the size of a nut, very hard and readily moreable, beneath the integument situate in the right mamma just above the nipple, not at all painful. She could nat account for it in any way. From the time she first

- It is but just to state that no such correct account as the above has been - It is but just to state that no such correct account as the sbove has been Fesished of the history of this case. The report in the Lancet of 31st Jan.

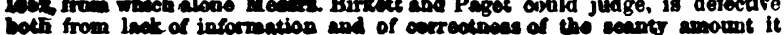
cappliea. noticed the tumour it gradually increased in size, till it bo came as large as an egg. It remained for some time of this size, and it was perfectly movesble benenth the skin, and painless, till three months ago, when it rapidly enlarged and became the seat of a sharp, shooting pain, which she compares to the sensation of a dog gnawing a bone; this pain was most severe at night. She had grown much thinner during the last three months, but no weaker, her appotite remaining good.

State on Admission. She was robust and healthy looking. The tumour in the right mamma was nearly hemispherical, about four inches in the maximum diameter. The skin, of natural colour, did not appear connected with it in the slightest degree, with the exception of slight retraction of the nipple. The tumour was very firm and solid, but one or two points could be detected on carcful examination, somewhat softer than the rest of the surface. When touched, it was only painful at a point on the right side. It was, however, very painful at night. She said it got larger and more painful every day. A group of indurated lymphatic glands was felt in the right axilla.

On the 18th June, the mamma as well as the axillary glands were removed by the knife. The progress of the case was exceedingly favourable; and on the 3rd July the patient was discharged in very good health with the wound neariy healed; but before the end of August, while I was acting as house-surgeon, she returned to the hospital with an affection of the cicatrix, presenting all the characters of secondary cancer. Before operation, there was some doubt as to the nature of the tumour; the softish points detected on palpating its surface were regarded as cysts, and notwithstanding the patient's age, the serere gnawing nocturnal pain, retraction of the nipple and enlargement of the lymphatic glands, the cystic formations were regarded as indications of the benignancy of the tumour, and it was diagnosed for cystic sarcoma. No cancer-cells appearing upon its being submitted to careful microscopic examination, the diagnosis of benignancy was held to be indisputably confirmed, and accordingly a favourable prognosis was pronounced. No notes were taken of the microscopic examination, but I perfectly remember observing at the time that all the specimens which I placed in the field contained a large number of compound granular corpuscles; that they were the most beautiful ones I had ever seen; and it was only then that I whs convinced that the delicate objects depicted under that name in Lebert's Atlas de Physiologie Pathologique, really exist in nature. It is not irrelevant to state that $I$ was in no degree prepared to discover histological evidence of benignancy myself; for before the operation I had tenaciously held to the opinion I had formed on first seeing the case, as to its being a bonci fide cancer.

This case having been reported in the Lasscet of 31st January, 1852, under the head of " Recurrence of a Cystic Sarcoma of the Breast," Mr. Birkett in the subsequent number of that journal called attention to the subject, for the reason of its being so "important in a practical as well as pathological point of view". After adducing reasons why the case must be regarded as one of carcinoma succeeding cystic sarcoma, rather than as a recurrence of the latter disease, Mr. Birkett remarks, "tilc derelopment of carcinoma subsequent to cysto-sarcoma is happily very rare, and this case is a valuable contribution to our imperfect knowledge of the natural history of this form of mammary disease. A case of this kind is reported hy Dr. Bruck (die Diagnose der bösartigen Geschwülste, case ix, s. 9i), which was observed in the clinique of Professor Chelius. The heads of the case are as follows. A cyst containing fluid and intracystic growths was removed from the right mamma. The patient continued to enjoy good health for twelve years. A tumour was then developed in the same breast, which with some axillary glands werc removed. This tumour is described by the name of carcinoma reticulare. The disease returned, infiltrated the skin around the cicatrix and the muscles of the mammary region, and the roman at last died. The necropsy revealed the existence of several carcinomatous growths in various regions of the 